\title{
Protective Effect of ATRA on Bleomycin Induced Lung Fibrosis in Rat
}

\section{Serairi Beji Raja', Msilini Najoua², Abidi Anouar ${ }^{3}$, Saidi Oussama' ${ }^{1}$, Jameleddine Saloua $^{3}$ and Ksouri Riadh ${ }^{4 *}$}

${ }^{1}$ High School of Health Sciences, Tunis, Tunisia

${ }^{2}$ Unité de Physiologie et de Biochimie de la Tolérance au Sel chez les Plantes, Faculté des Sciences de Tunis, Université Tunis El Manar, Campus Universitaire, 2092

Tunis, Tunisia

${ }^{3}$ Research Unit 03/UR/08-05, Pulmonary Fibrosis: Prevention and Treatment, Faculty of Medicine of Tunis, Tunisia

${ }^{4}$ Laboratoire des Plantes Extrêmophiles, Centre de Biotechnologie à la Technopole de Borj Cédria (CBBC), BP 901,2050 Hammam-lif, Tunisia

\begin{abstract}
All-trans-retinoic acid (ATRA), an active metabolite of vitamin A, is known to affect cell differentiation, proliferation, and development. Pulmonary fibrosis is one of the most common chronic interstitial lung diseases with high mortality rate after diagnosis and limited successful treatment. The aim of this study is to assess the effects of ATRA against bleomycin-induced pulmonary fibrosis in rats. Animals were intratracheally instillated with bleomycin and/or intraperitoneally administered with ATRA. On day 28, rats were sacrificed and histological changes in the lungs were evaluated. Moreover, malondialdehyde (MDA) content, superoxide dismutase (SOD), catalase (CAT) and glutathione peroxidase (GPX) activities in serum and lung, were achieved. Results displayed that rat body weight decreased while fibrosis score and inflammatory index in lung tissue were significantly increased, after bleomycin instillation. Administration of bleomycin followed by ATRA reduced bleomycin-induced weight loss, decreased the lung index and the inflammatory indices. Histopathological examination confirmed the antifibrotic effect of ATRA which apparently attenuated the degree of pulmonary fibrosis. In addition, data showed that ATRA significantly increased SOD, CAT and GPx levels as compared to bleomycin group (G2) concomitant to the decrease of MDA content in lung homogenates. These findings indicate that ATRA treatment significantly attenuated the increased pulmonary damage induced by bleomycin.
\end{abstract}

Keywords: Antioxidant enzymes; ATRA; Bleomycin; MDA; Pulmonary fibrosis

\section{Introduction}

Idiopathic pulmonary fibrosis (IPF) is a specific form of chronic progressive fibrotic lung disease with the 3 -and 5 -year mortality rates at approximately 50 and $80 \%$ of cases, respectively, in the absence of lung transplantation [1]. Several risk factors are likely culprits. They include cigarette smoking [2], chemotherapeutic drugs [3], aerosolized environmental toxins, exposure to radiotherapy [4], and genetic predispositions [5]. Pathogenesis of IPF includes inflammation, apoptosis, oxidative stress, and epithelial mesenchymal transition [6]. Although significant progress has been made in understanding the molecular mechanisms of the pathogenesis of IPF, the treatment is still unfortunately not yet available.

The last decade, pharmacologic trials for treating IPF have shown disappointing and controversial results. King et al. [7] concluded that treatment with interferon gamma- $1 b$, compared to placebo, did not improve survival for patients with idiopathic pulmonary fibrosis. Later, the same author concluded at the failure of the treatment with bosentan [8]. Similar results were also found by Raghu [9] who showed that Ambrisentan was not effective in treating IPF and may be associated with an increased risk for disease progression and respiratory hospitalizations. Furthermore, a number of well-tolerated drugs such as pirfenidone treatment [10] have many side effects being gastrointestinal and photosensitivity.

Until today, lung transplant is often the only viable treatment option and no therapy has been proven to prolong survival [11]. Therefore, new drugs with better efficacy and tolerability for the pulmonary fibrosis were needed. It is established that the derivatives of vitamin A retinoids, 9-cis and 13-cis retinoic acid (RA), play a key role in cell proliferation and differentiation in many tissues, particularly the epitheliums. The currently available in vitro and in vivo reports indicate that RA plays a protective role and prevents ECM accumulation in the lung, thereby protecting against pulmonary fibrosis [12-15]. EstebanPretel et al. [16] showed that lack of retinoids thickens the alveolar basement membrane and increases collagen IV, which are reversed by retinoic acid, the main biologically active vitamin A form. However, they also recorded that RA treatment increased oxidative stress and lipid peroxidation most likely because of auto-oxidation of RA due to the high $\mathrm{pO}_{2}$ in the lung that produced superoxide and carboncentered radicals.

Regarding the effect of RA isomers on antioxidant systems, low concentrations of RA (0.1-100 nM) did not show, in rat sertoli cells, any effect on the activity of antioxidant enzymes, whereas high concentrations $(1-10 \mu \mathrm{M})$ controlled the activity of antioxidant enzymes [17]. In addition, in the neuronal apoptosis case, RA is reported to help the antioxidant system by enhancing the protein levels of SOD-1 $(\mathrm{Cu}-$ \&Zn-SOD) and SOD-2 (Mn-SOD), and reducing the concentration of ROS within cells [18]. However, Hong and Lee-Kim [19], showed that RA isomers did not show any effect on the SOD activity in breast cancer cells, which strongly suggest differences in the protein levels of SOD. Authors also added that $1 \mu \mathrm{M}$ of all-trans RA concentration showed differences in the activities of catalase and glutathione peroxidase while showing no difference in the activity of SOD.

Because such divergent and contradictory effects are reported in the literature [20] and among RA isomers, all-trans RA may be the most potential inducer of apoptosis and modulator of antioxidant enzymes in cells such ER-positive MCF-7 human breast cancer cells [19], we propose to test the effects of ATRA on enzymatic oxidative system, in bleomycin-induced lung fibrosis in rats.

*Corresponding author: Ksouri Riadh, Laboratoire des Plantes Extrêmophiles Centre de Biotechnologie à la Technopole de Borj Cédria (CBBC), BP 901, 2050 Hammam-lif, Tunisia, Tel: +216-98642356; Fax: +216-79325638; E-mail: riadh.ksouri@cbbc.rnrt.tn

Received July 25, 2014; Accepted August 20, 2014; Published August 22, 2014

Citation: Raja SB, Najoua M, Anouar A, Oussama S, Saloua J, et al. (2014) Protective Effect of ATRA on Bleomycin Induced Lung Fibrosis in Rat. Med chem 4: 611-616. doi:10.4172/2161-0444.1000202

Copyright: ( 2014 Raja SB, et al. This is an open-access article distributed under the terms of the Creative Commons Attribution License, which permits unrestricted use, distribution, and reproduction in any medium, provided the original author and source are credited. 


\section{Materials and Methods}

\section{Animals}

Healthy male albino Wistar rats weighing $215 \pm 15 \mathrm{~g}$, purchased from Tunis Pasteur Institute, were used during the present study. They were maintained under controlled conditions of light and temperature. Rats were provided with food and water ad libitum and maintained in animal housing at a controlled temperature $\left(22 \pm 2^{\circ} \mathrm{C}\right)$ with a 12 $\mathrm{h}$ light-dark cycle. All experiments were performed according to the recommendations of ethic committee of Tunis University for care and International Council of Laboratory Animal Science.

\section{Model of bleomycin-induced pulmonary fibrosis}

An animal model of bleomycin induced pulmonary fibrosis as reported earlier [21], was used in this study. All rats underwent anesthesia by intraperitoneal injection of $100 \mu \mathrm{g} / \mathrm{g}$ of pentobarbital sodium solution. Each anesthetized rat was immediately suspended from a gallows. Induction of fibrosis was done by an intra-tracheal injection of $4 \mathrm{mg} / \mathrm{kg}$ body weight of bleomycin sulfate solution (Bleomycin ${ }^{\oplus}$, Laboratories Aventis, France) in $50 \mu \mathrm{l}$ saline, as previously described [21].

\section{Study design}

Three days after the induction of fibrosis, thirty-two animals were divided randomly in four experimental groups with eight animals each.

G1: The negative control group animals received an intra-tracheal injection of normal saline instead of bleomycin (Control group).

G2: The positive control group animals were subjected to a single intra-tracheal instillation of bleomycin (Bleo group).

G3: The bleomycin plus ATRA group animals received the same amount of bleomycin as the bleomycin group animals and three days after, they were treated with ATRA ( $3 \mathrm{mg} / \mathrm{kg}$ intraperitoneally) weekly for 28 days (Bleo+ATRA group)

G4: The ATRA group received an intra-tracheal injection of normal saline and was then treated with ATRA weekly for 28 days (ATRA group).

\section{Sample collection and analytical procedures}

After 4 weeks of treatment, animals were anesthetized by injecting intraperitoneally $100 \mu \mathrm{g} / \mathrm{g}$ of pentobarbital sodium solution. Blood was drawn from the abdominal aorta under anesthesia and then the animals were scarified immediately. After separation, the serum was stored at $-70^{\circ} \mathrm{C}$ until assayed as described below. A section of the diaphragm and the anterior thorax allowed us to extract the heart-lung block. Lung promptly removed and weighed. The Right lung was stored at $-70^{\circ} \mathrm{C}$ for detecting MDA, SOD, CAT, and GPx. The left lung was immersed in $10 \%$ buffered formaldehyde for histological examination.

\section{Body weight and lung index}

In the course of the experiment, the body weight of rats was measured every 7 days, and the weight gain of rats in each group was compared. After sacrifice, the lungs were removed, trimmed of extraneous tissue, rinsed, and weighed. The ratio of net lung weight (mg) to the body weight ( $\mathrm{g}$ ) for each rat was used as the lung index.

\section{Histochemical examination}

After sacrificing the animals, the left lung was carefully excised and fixed for one week in $10 \%(w / v)$ PBS-buffered formaldehyde solution at room temperature, dehydrated using graded ethanol and embedded in paraffin. The paraffin-embedded tissues were cut to $5 \mu \mathrm{m}$ thicknesses with a microtome. To evaluate the histopathological changes, the sections were subjected to haematoxylin and eosin (HE) staining. To identify the density of the accumulated collagen fibers Masson's trichrome (MT) staining was performed. Histological grading of lesions was performed using a blinded semi quantitative scoring system for extent and severity of inflammation and fibrosis in lung parenchyma. The severity of inflammation was estimated using the semi quantitative grading system which considers the following categories: Grade $0=$ "absence of inflammation", Grade 1="minimal inflammation", Grade 2="minimal to moderate inflammation", Grade 3="moderate inflammation with thickening of alveolar walls", Grade 4="moderate to severe inflammation" and Grade 5="severe inflammation with presence of follicles which replace the parenchyma". The severity of interstitial fibrosis was also determined using the semi quantitative grading system, described by Ashcroft et al. [22]. The entire lung section was observed at a $\times 100$ magnification and a score ranging from 0 (normal lung) to 8 (total fibrosis) was assigned. The adopted categories of grading pulmonary fibrosis were as follows: Grade $0=$ "normal lung", Grade 1="minimal fibrous thickening of alveolar or bronchial walls", Grades 2 to 3="moderate thickening of walls without obvious damage to lung architecture", Grades 4 to $5=$ "increased fibrosis with definite damage to lung architecture and formation of fibrous bands or small fibrous mass", Grades 6 to 7="severe distortion of structure and large fibrous areas", "honeycomb lung" was placed in this category; Grade $8=$ "total fibrotic obliteration of the field". The mean score of all fields was taken as the fibrosis score of that lung section.

\section{Determination of lipid peroxidation level in serum and lung and antioxidant enzymes activities}

The right lung tissue homogenates of the control and experimental groups of animals were prepared with $0.1 \mathrm{M}$ Tris- $\mathrm{HCl}$ buffer $(\mathrm{pH} 7.4)$ at $4^{\circ} \mathrm{C}$ using a tissue homogeneiser. The resulting tissue homogenates were used for biochemical measurements.

MDA, a reactive carbonyl compound formed upon the decomposition of polyunsaturated fatty acid peroxides [23], was measured as an indicator of oxidative stress in lung homogenate and in serum using the method of Ohkawa et al. [24] and Bueje and Aust [25], with little modifications. The levels of MDA were expressed as $\mathrm{nmol} / \mathrm{mg}$ protein $\left(\varepsilon 532=1.56 \times 105 \mathrm{M}^{-1} \mathrm{~cm}^{-1}\right)$. Protein level in plasma was determined by means of a colorimetric assay kit specific for total protein using a Biuret method. The levels of protein were expressed in g/L [21].

The activities of three antioxidant enzymes: SOD, CAT and GPx were determined in lung homogenate and in serum. SOD activity was measured according to the method of Beyer and Fridovich [26]. CAT activity was determined using the method of Aebi [27] and GPx activity was measured according to the method of Flohe and Gunzler [28].

\section{Protein quantification in lung}

Protein content in lung samples was assayed as described by Lowery et al. [29], using bovine serum albumin as standard.

\section{Statistical analysis}

Statistical analysis was performed with Statistica ${ }^{\mathrm{TM}}$ software, using one-way analysis of variance (ANOVA). Statistical assessments of differences between mean values were performed by Duncan's multiple range test at $P \leq 0.05$. 


\section{Results}

\section{Effects of ATRA on weight increase and lung indices in rats}

It is worth noting that body weights of four groups were not significantly different at the beginning of treatment (G1: $210 \pm 7 \mathrm{~g} ; \mathrm{G} 2$ : $221 \pm 8$ g; G3: $215 \pm 4$ g; G4: $213 \pm 10 \mathrm{~g}$ ). Moreover, no rats died unexpectedly during the experimental procedure.

The difference in body weight between days 0 and 28 was determined as the increase in body weight (Table 1). Control and ATRA groups showed a significant and progressive increase in body weight gain, during the four weeks of treatment. However, in the case of rats of G2, a loss in body weight was recorded as compared with the control rats. In G3, ATRA administration significantly restored the loss in body weight, from the second week of treatment (Table 1). Simultaneously, the increased lung indices (lung weight/body weight) of the bleomycin-treated animals compared to negative control rats (7.9 vs $4.2 \mathrm{mg} / \mathrm{g}$; $\mathrm{p}<0.01$ ) was prominently reduced when treated with ATRA ( $4.5 \mathrm{mg} / \mathrm{g}$; Table 2).

\section{Histological analysis}

To observe the pathological changes in lung, HE staining and MT staining were performed. Then, the histological evaluation of lung sections 4 weeks after the BLM injection revealed evidence of obvious alveolar wall thickening, massive infiltration of inflammatory cells, and excessive deposition of mature collagen in the interstitium. However, after ATRA treatments, the pathological changes in the lung tissues were relieved. In fact, the average inflammatory indices listed in Table 2 , showed that the inflammation score for group 2 was 5.5 leading to severe inflammation in this group, not having received injection of ATRA. Treatment with ATRA (G3) generated a significantly lowered score $(2.4 \mathrm{p}<0.01)$, indicating a moderate inflammation with thickening of the alveolar wall. The Ashcroft score was also measured. Again, animals treated with ATRA (G3) induced a significant decrease of the FS when compared to animals received only Bleomycin (G2) (3.5 \pm 0.71 vs $6.7 \pm 1.66$ ). Lung tissues from the $\mathrm{G} 1$ and $\mathrm{G} 4$ groups displayed a normal structure and no pathologic changes under a light microscope (data not shown)

\section{Determination of antioxidant enzymes activities and lipid peroxidation level}

The levels of MDA and the antioxidant activities of GPx, CAT and SOD were depicted in the plasma and lung tissue of control and experimental rats (Figures 1 and 2). A significant rise in the levels of MDA in the plasma and lung tissue was observed in the bleomycin treated animals $(\mathrm{G} 2)(\mathrm{p}<0.05)$. This effect was accompanied by a decrease in the enzymatic activities of GPx, SOD and CAT. The administration of ATRA (G3), significantly decreased MDA level and restored the antioxidant enzyme activities to near normal $(\mathrm{p}<0.05)$ (Figures 1 and 2).

\section{Discussion}

In this study, we showed the therapeutic effects of ATRA on the progression of lung fibrosis in blemycin-treated mice. Our results confirm by the determination of the inflammatory index and the fibrosis index that ATRA appears to exert its effect through inhibition of both inflammation and oxidative stress in bleomycin-induced pulmonary fibrosis in rat. In this report, we showed in the Table 2 a very significant difference of the IF between G2 and G3 groups. Indeed, inflammation is decreased from moderate to severe for the Group 2 $(\mathrm{IF} \approx 5)$ to moderate with thickening of the alveolar wall $(\mathrm{IF} \approx 2)$ for the
Group 3. We conclude that the ATRA has decreased the inflammatory effect of fibrosis.

In addition, fibrosis index is decreased from index 6 (between moderate fibrous thickening and preserved architecture, and disorganized architecture with bands of fibrosis and fibrous nodules of small sizes.) for Group 2 to index 3 (between slight thickening of the alveoli or bronchioles and moderate fibrous thickening and preserved architecture) for Group 3. The ATRA has a positive effect by delaying the development of fibrosis, with a very significant difference of the fibrosis index between the G2 and G3 groups.

This experiment confirm that ATRA, a vitamin A derivative, has an anti-inflammatory [30-33] and various anti-fibrotic effects [15,34] on the IPF, a result revealed by a very significant difference between the inflammatory index and the score of fibrosis in the groups receiving injections of ATRA and those who has not received. In this case, ATRA has been shown to antagonize the effects of platelet-derived growth factor (PDGF)-BB [35] and tumor necrosis factor (TNF- $\alpha$ ) on target cells. These cytokines have been shown to play key roles in bleomycininduced lung fibrosis [36,37]. Retinoids have also anti-fibrotic properties. Indeed, ATRA decreases steady state and transforming growth factor (TGF- $\beta$ ) induced $\alpha 1$ (I) collagen gene expression in human lung fibroblast cell lines [38]. ATRA has also been shown to inhibit anchorage-dependent growth of human neonatal lung fibroblasts and fibroblasts from adult fibrotic lung tissue [39].

Taken together, these data suggested that ATRA might be of significant benefit in fibrotic lung disease. We therefore investigated the effect of ATRA in bleomycin-induced lung fibrosis in rats to determinate the oxidative stress (OS) induced by bleomycin in lung cells. OS is known as an undoubtedly factor in determining the impairment of pulmonary structure and function pulmonary responsiveness. The way in which this stress is induced can be very important for the development of lung diseases. In the light of the role that antioxidants play in the development of OS, we focused on pulmonary impact of OS induced by bleomycin alone or in combination with ATRA.

The extent of inflammation-induced oxidative lung tissue injury was evaluated by measuring the levels of MDA in lung tissue homogenates. MDA is formed upon decomposition of the polyunsaturated fatty acids on exposure to free radicals. Following this chronic treatment, our results showed clearly that treatment with bleomycin causes an increase in the levels of MDA in the lungs. We also recorded a decrease of the level of MDA after combined exposure of rats to bleomycin and ATRA.

\begin{tabular}{|c|c|c|c|c|}
\hline & \multicolumn{4}{|c|}{ Body weight gain } \\
\hline Group & Day 7 & Day 14 & Day 21 & Day 28 \\
\hline G1 & $20.4 \pm 1.1 \mathrm{~d}$ & $40.1 \pm 2.6 \mathrm{c}$ & $60.2 \pm 2.1 \mathrm{~b}$ & $83.7 \pm 2.8 \mathrm{a}$ \\
\hline G2 & $-12.9 \pm 1.8 \mathrm{~g}$ & $-23.5 \pm 2.2 \mathrm{~h}$ & $-34.5 \pm 1.4 \mathrm{i}$ & $-38.1 \pm 2.1 \mathrm{i}$ \\
\hline G3 & $-8.0 \pm 0.8 \mathrm{~g}$ & $-7.9 \pm 2.5 \mathrm{fg}$ & $-5.5 \pm 3.0 \mathrm{f}$ & $9.00 \pm 1.0 \mathrm{e}$ \\
\hline G4 & $17.7 \pm 1.5 \mathrm{~d}$ & $35.4 \pm 2.4 \mathrm{c}$ & $55.4 \pm 3.9 \mathrm{c}$ & $67.2 \pm 3.2 \mathrm{a}$ \\
\hline
\end{tabular}

Table 1: Effect of ATRA and/or bleomycin treatment on body weight gain $(\Delta \mathrm{g})$ of treated rats. Values are the means of 8 replicates \pm SD. Different letters indicate significant differences at $P \leq 0.05$ as determined by Duncan's multiple range tests.

\begin{tabular}{|c|c|c|c|}
\hline Groups & Lung index & Inflammatory score & Fibrosis score \\
\hline G1 & $4.23 \pm 0.05 \mathrm{~b}$ & $0.0 \pm 0.0 \mathrm{c}$ & $0.0 \pm 0.0 \mathrm{c}$ \\
\hline $\mathrm{G} 2$ & $7.86 \pm 0.19 \mathrm{a}$ & $5.5 \pm 0.18 \mathrm{a}$ & $6.75 \pm 0.16 \mathrm{a}$ \\
\hline $\mathrm{G} 3$ & $4.47 \pm 0.12 \mathrm{~b}$ & $2.37 \pm 0.18 \mathrm{~b}$ & $3.50 \pm 0.19 \mathrm{~b}$ \\
\hline G4 & $4.25 \pm 0.04 \mathrm{~b}$ & $0.0 \pm 0.0 \mathrm{c}$ & $0.0 \pm 0.0 \mathrm{c}$ \\
\hline
\end{tabular}

Table 2. Effect of ATRA and/or bleomycin treatment on lung index, inflammatory and fibrosis score in treated rats. Values are the means of 8 replicates $\pm S D$. For each parameter, different letters indicate significant differences at $P \leq 0.05$ as determined by Duncan's multiple range tests. 


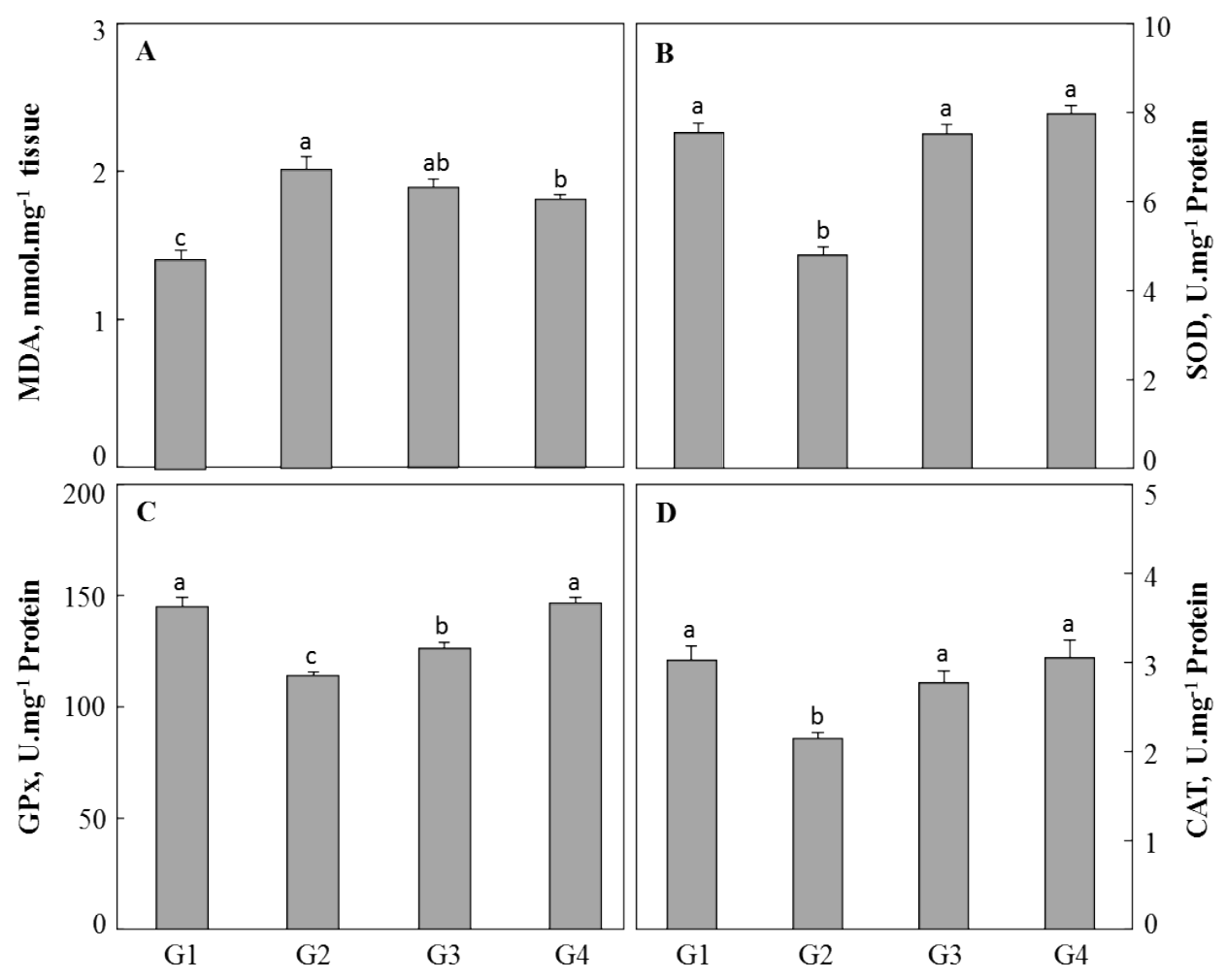

Figure 1: Effect of ATRA and/or bleomycin treatment on MDA levels and SOD, GPx and CAT activities in lung tissues of treated rats. Values are the means of 8 replicates \pm SD. For each parameter, different letters indicate significant differences at $P \leq 0.05$ as determined by Duncan's multiple range tests.

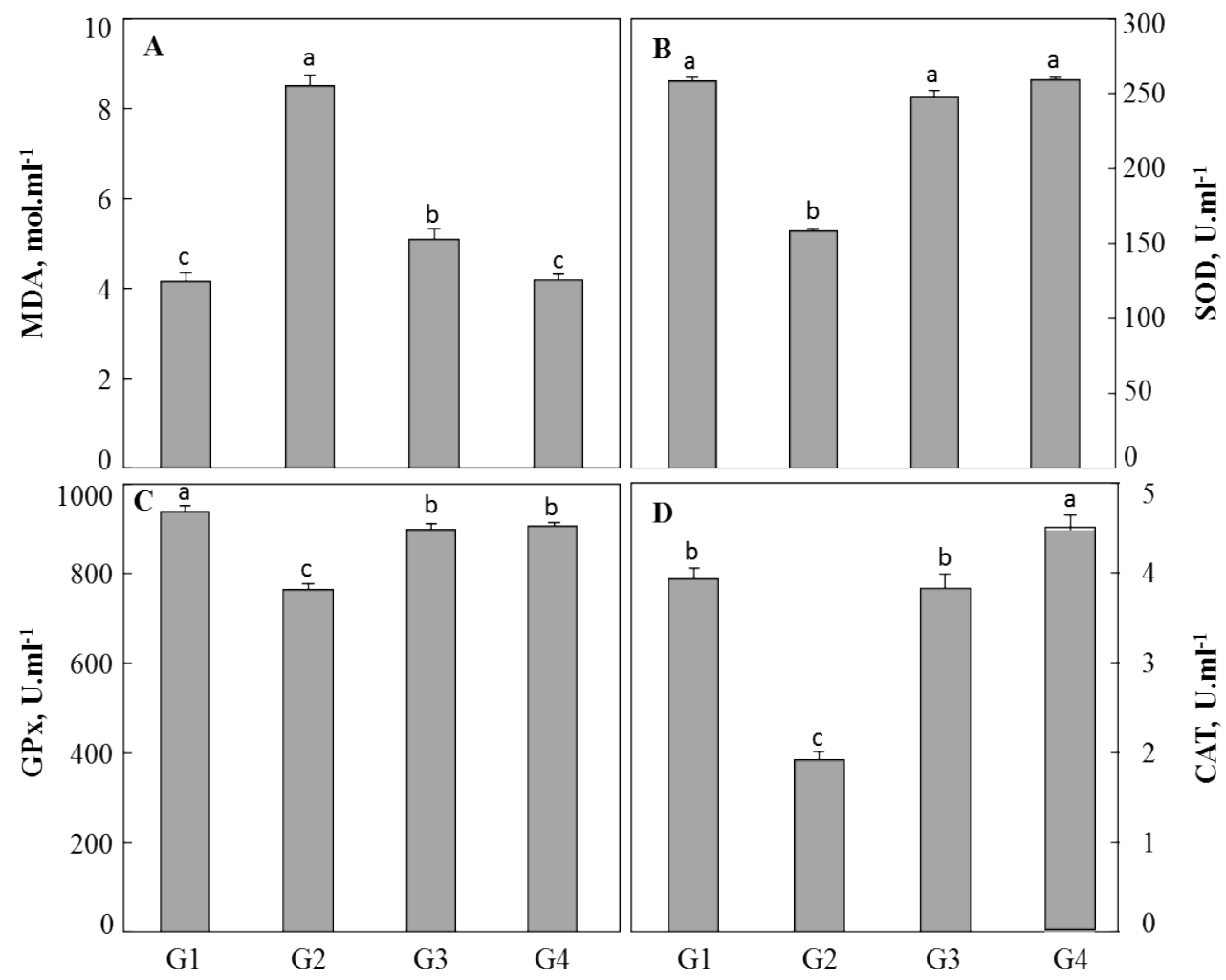

Figure 2: Effect of ATRA and/or bleomycin treatment on MDA levels and SOD, GPx and CAT activities in plasma of treated rats. Values are the means of 8 replicates \pm SD. For each parameter, different letters indicate significant differences at $P \leq 0.05$ as determined by Duncan's multiple range tests. 
In this case, we suggest that bleomycin causes intracellular formation of ROS that attack the cell membrane and organelles, which causes an increase in the MDA level, and that ATRA prevents this excessive level of ROS which decreases therefore the rate of MDA detected [40].

On the other hand, we have explored the levels of SOD, catalase and glutathione peroxidase which represents the most important defense enzymatic complexes against every oxidative stress and can provide the presence and the intensity of the oxidative stress induced by bleomycin. The administration of bleomycin alone led to a significant reduction in the enzymatic activity of SOD in the lung tissues. We may explain this decrease in SOD activity by a possible role of bleomycin by transforming the SOD in an inactive form. On the other side, the treatment with ATRA increased the SOD activity in the lung to a similar rate compared to the control group. It is assumed in this case that the ATRA could activate endogenous systems for the capture/ inactivation of bleomycin inducing an increase of the SOD rate.

In a second step, we observed after following dosage of antioxidant components, that the activity of catalase is decreased in the group treated with bleomycin alone versus control group. The addition of ATRA appears to increase significantly the catalase activity compared to the group treated with bleomycin alone, and this result suggest that ATRA, the active form of vitamin A, has strengthened the antioxidant activity of catalase in the lung of rats previously treated with a high dose of bleomycin.

Finally, we noticed an increase in glutathione peroxidase in the lung compared to the control group after the administration of bleomycin alone. This is probably due to the development of an adaptive mechanism stimulating the activity of glutathione peroxidase after chronic exposure to bleomycin, to decrease oxidative stress induced. After the addition of ATRA, there was a significant decrease of its rate and it becomes similar to control.

We can highlight by these results, that ATRA regulates the antioxidant enzymes activities in response to bleomycin treatment by enhancing the activity of SOD and catalase and decreasing that of glutathione peroxidases.

\section{Conclusion}

This study shows that ATRA, a vitamin A derivative, acts as a systemic antioxidant, participating in the modulation of diverse redox mechanisms involved in physiopathlogical processes. ATRA can decrease the inflammatory response and the fibrosis score in the lung of rats treated by bleomycin which may lead to the development of novel strategies using ATRA in the treatment of IPF. Furthermore, histological evidence supported the ability of ATRA to attenuate bleomycin-induced lung fibrosis, these findings provide evidence that ATRA may serve as a target for potential protective treatment of lung fibrosis.

\section{References}

1. Raghu G, Collard HR, Egan JJ, Martinez FJ, Behr J, et al. (2011) An official ATS/ERS/JRS/ALAT statement: idiopathic pulmonary fibrosis: evidence-based guidelines for diagnosis and management. Am J Respir Crit Care Med 183: 788-824

2. Ley B, Collard HR (2013) Epidemiology of idiopathic pulmonary fibrosis. Clin Epidemiol 5: 483-492.

3. Pietrofesa RA, Turowski JB, Arguiri E, Milovanova TN, Solomides CC, et al. (2013) Oxidative Lung Damage Resulting from Repeated Exposure to Radiation and Hyperoxia Associated with Space Exploration. J Pulm Respir Med 3.

4. Schwaiblmair M, Behr W, Haeckel T, MÃarkl B, Foerg W, et al. (2012) Drug induced interstitial lung disease. Open Respir Med J 6: 63-74.
5. Wolters PJ, Collard HR, Jones KD (2014) Pathogenesis of idiopathic pulmonary fibrosis. Annu Rev Pathol 9: 157-179.

6. Yang T, Chen M, Sun T (2013) Simvastatim attenuates TGF-ß1-induced epithelial-mesenchymal transition in human alveolar epithelial cells. Cell Physiol Biochem 3: 863-874.

7. King TE Jr, Albera C, Bradford WZ, Costabel U, Hormel P et al. (2009) Effect of interferon gamma-1b on survival in patients with idiopathic pulmonary fibrosis (INSPIRE): a multicentre, randomised, placebo-controlled trial. Lancet 374 222-228.

8. King TE Jr, Brown KK, Raghu G, du Bois RM, Lynch DA, et al. (2011) BUILD-3 a randomized, controlled trial of bosentan in idiopathic pulmonary fibrosis. Am J Respir Crit Care Med 184: 92-99.

9. Raghu G, Behr J, Brown KK, Egan JJ, Kawut SM, et al. (2013) Treatment of Idiopathic Pulmonary Fibrosis With Ambrisentan: A Parallel, Randomized Trial. Ann Intern Med 158: 641-649.

10. Cottin $V(2013)$ The role of pirfenidone in the treatment of idiopathic pulmonary fibrosis. Respir Res 14 Suppl 1: S5.

11. Swigris JJ, Kuschner WG, Kelsey JL, Gould MK (2005) Idiopathic pulmonary fibrosis: challenges and opportunities for the clinician and investigator. Chest 127: 275-283.

12. Tabata C, Kadokawa Y, Tabata R, Takahashi M, Okoshi K, et al. (2006) Alltrans-retinoic acid prevents radiation-or bleomycin-induced pulmonary fibrosis. Am J Respir Crit Care Med 174: 1352-1360.

13. Tabata C, Kubo H, Tabata R, Wada M, Sakuma K, et al. (2006) All-trans retinoic acid modulates radiation-induced proliferation of lung fibroblasts via IL-6/IL-6R system. Am J Physiol Lung Cell Mol Physiol 290: L597-606.

14. Dong XS, Hu XB, Liu W, Sun YQ, Liu Z (2012) Effects of RNA interferenceinduced $S$ mad3 gene silencing on pulmonary fibrosis caused by paraquat in mice. Exp Biol Med (Maywood) 237: 548-555.

15. Ozer EA, Kumral A, Ozer E, Duman N, Yilmaz O, et al. (2005) Effect of retinoic acid on oxygen-induced lung injury in the newborn rat. Pediatr Pulmonol 39: 35-40.

16. Esteban-Pretel G, Marín MP, Renau-Piqueras J, Sado Y, Barber T, et al (2013) Vitamin A deficiency disturbs collagen IV and laminin composition and decreases matrix metalloproteinase concentrations in rat lung. Partial reversibility by retinoic acid. J Nutr Biochem 24: 137-145

17. Conte da Frota ML Jr, Gomes da Silva E, Behr GA, Roberto de Oliveira M, Dal-Pizzol F, et al. (2006) All-trans retinoic acid induces free radical generation and modulate antioxidant enzyme activities in rat sertoli cells. Mol Cell Biochem 285: 173-179.

18. Ahlemeyer B, Bauerbach E, Plath M, Steuber M, Heers C, et al. (2001) Retinoic acid reduces apoptosis and oxidative stress by preservation of SOD protein level. Free Radic Biol Med 30: 1067-1077.

19. Hong TK, Lee-Kim YC (2009) Effects of retinoic acid isomers on apoptosis and enzymatic antioxidant system in human breast cancer cells. Nutr Res Pract 3 77-83.

20. Zhou TB, Drummen GP, Qin YH (2012) The controversial role of retinoic Acid in fibrotic diseases: analysis of involved signaling pathways. Int J Mol Sci 14 : 226-243.

21. Yacoubi L, Rabaoui L, Hamdaoui MH, Fattouch S, Serairi R, et al. (2011) Anti-oxidative and anti-inflammatory effects of Trigonella foenum-graecum Linnaeus, 1753 (Fenugreek) seed extract in experimental pulmonary fibrosis. J Med Plant Res 5: 4315-4325

22. Ashcroft T, Simpson JM, Timbrell V (1988) Simple method of estimating severity of pulmonary fibrosis on a numerical scale. J Clin Pathol 41: 467-470.

23. Esterbauer H, Schaur RJ, Zollner H (1991) Chemistry and biochemistry of 4-hydroxynonenal, malonaldehyde and related aldehydes. Free Radic Biol Med 11: 81-128.

24. Ohkawa H, Ohshi N, Yagi K (1979) Assay for lipid peroides in animals' tissues by thiobarbituric acid reaction. Anal Biochem 95: 351-358.

25. Bueje JA, Aust SD (1978) Microsomal lipid peroxidation. Method Enzymol 52 303-310.

26. Beyer WF Jr, Fridovich I (1987) Assaying for superoxide dismutase activity: some large consequences of minor changes in conditions. Anal Biochem 161 559-566. 
Citation: Raja SB, Najoua M, Anouar A, Oussama S, Saloua J, et al. (2014) Protective Effect of ATRA on Bleomycin Induced Lung Fibrosis in Rat. Med chem 4: 611-616. doi:10.4172/2161-0444.1000202

27. Aebi H (1984) Catalase in vitro. Methods Enzymol 105: 121-126.

28. Flohe L, Gunzler WA (1984) Assays of glutathione peroxidase. Methods Enzymol 105: 114-121.

29. Lowry OH, Rosebrough NJ, Farr AL, Randall RJ (1951) Protein measurement with the Folin phenol reagent. J Biol Chem 193: 265-275.

30. Fumarulo R, Conese M, Riccardi S, Giordano D, Montemurro P, et al. (1991) Retinoids inhibit the respiratory burst and degranulation of stimulated human polymorphonuclear leukocytes. Agents Actions 34: 339-344.

31. Akdeniz N, Calka O, Ozbek H, Metin A (2005) Anti-inflammatory effects of tretinoin (all-trans-retinoic acid) $0.1 \%$ and adapalene $0.1 \%$ in rats. Clin Exp Dermatol 30: 570-572.

32. Nozaki Y, Yamagata T, Sugiyama M, Ikoma S, Kinoshita K, et al. (2006) Anti-inflammatory effect of all-trans-retinoic acid in inflammatory arthritis. Clin Immunol 119: 272-279.

33. Esteban-Pretel G, Marín MP, Renau-Piqueras J, Barber T, Timoneda J (2010) Vitamin A deficiency alters rat lung alveolar basement membrane: reversibility by retinoic acid. J Nutr Biochem 2: 227-236.

34. Segel MJ, Or R, Tzurel A, Lucey EC, Goldstein RH, et al. (2001) All-transretinoic acid (ATRA) is of no benefit in bleomycin-induced lung injury. Pulm Pharmacol Ther 14: 403-407.
35. Ping D, Boekhoudt G, Boss JM (1999) trans-Retinoic acid blocks plateletderived growth factor-BB-induced expression of the murine monocyte chemoattractant-1 gene by blocking the assembly of a promoter proximal Sp1 binding site. J Biol Chem 274: 31909-31916.

36. Piguet PF, Collart MA, Grau GE, Kapanci Y, Vassalli P (1989) Tumor necrosis factor/cachectin plays a key role in bleomycin-induced pneumopathy and fibrosis. J Exp Med 170: 655-663.

37. Rice AB, Moomaw CR, Morgan DL, Bonner JC (1999) Specific inhibitors of platelet-derived growth factor or epidermal growth factor receptor tyrosine kinase reduce pulmonary fibrosis in rats. Am J Pathol 155: 213-221.

38. Redlich CA, Delisser HM, Elias JA (1995) Retinoic acid inhibition of transforming growth factor-beta-induced collagen production by human lung fibroblasts. Am J Respir Cell Mol Biol 12: 287-295.

39. Torry DJ, Richards CD, Podor TJ, Gauldie J (1996) Modulation of the anchorage-independent phenotype of human lung fibroblasts obtained from fibrotic tissue following culture with retinoid and corticosteroid. Exp Lung Res 22: 231-244.

40. Pini A, Shemesh R, Samuel CS, Bathgate RA, Zauberman A, et al. (2010) Prevention of bleomycin-induced pulmonary fibrosis by a novel antifibrotic peptide with relaxin-like activity. J Pharmacol Exp Ther 335: 589-599. 